\title{
PAISAGENS, TERRITÓRIOS E PRESSÃO COLONIAL ${ }^{1}$
}

AILTON KRENAK ${ }^{2}$

Ailton: Boa tarde a todos vocês, queridos amigos e amigas que dedicam a sua tarde, que podia estar sendo aproveitada em qualquer outro espaço ou situação, para estar aqui me propiciando essa ocasião de conversa, de encontro nosso. Agradeço muito a presença de vocês e agradeço, em especial, esse querido professor Sergio, junto com seus colegas aqui do ILEA, que propiciaram a minha vinda para cá. Eu gostei muito de saber que existe aqui alguma referência a um termo que a primeira vez que eu ouvi ser pronunciado foi quando eu me juntei com os nossos parentes, o povo Kuna, que vive no Panamá, e que chama esse continente que nós chamamos de continente americano de "Abya Yala". Não sei se já foi compartilhado com vocês a origem dessa palavra que identifica essa Rede Abya Yala. "Abya Yala" evoca um território afetivo, talvez imaginário, de povos que viviam aqui nesse continente antes de iniciar as, digamos, "abordagens" no continente por povos que vieram de outras paisagens. Numa posição de resistência, numa posição de muito clara afirmação, de identidade dos povos originários dessa região do mundo, especialmente pensando a partir da América Central, onde estão os Maias, que

\footnotetext{
${ }^{1}$ Palestra conferida em evento promovido pela rede de pesquisa Abya Yala: epistemologias ameríndias em rede, no auditório do Instituto Latino-Americano de Estudos Avançados (ILEA), Campus do Vale, Universidade Federal do Rio Grande do Sul, na tarde do dia 6 de novembro de 2015. Transcrição realizada por Eduardo Schaan e Carmem Guardiola.

${ }^{2}$ Militante indígena dos direitos humanos. Nasceu em 1953, no Vale do Rio Doce, Minas Gerais, no povo dos Krenak. Em 1987, no contexto das discussões da Assembleia Constituinte, Ailton Krenak foi autor de um gesto marcante, logo captado pela imprensa e que comoveu a opinião pública: pintou o rosto de preto com pasta de jenipapo enquanto discursava no plenário do Congresso Nacional, em sinal de luto pelo retrocesso na tramitação dos direitos indígenas. Fundou e dirige a ONG Núcleo de Cultura Indígena. Dirige o Festival de Danças e Culturas Indígenas, na Serra do Cipó (MG). Autor de textos e artigos publicados em coletâneas no Brasil e exterior. E-mail: ailtonkrenak@ gmail.com .
} 
constituem uma população grande na América Central, e seus vizinhos, como os Kuna, na região em que hoje está o Panamá, já constituiu nações muito conscientes do território que ocupavam, do território onde viviam, e tinham uma percepção muito clara de que nós estávamos, lá naquele tempo das primeiras colonizações que aconteceram aqui na América, que estávamos sofrendo uma invasão que ia alterar profundamente a noção de território que os antigos, os nossos antepassados antigos, tinham sobre esse lugar que nós passamos cada vez mais a identificar como continente americano, América, né? Outro dia mesmo eu estava conversando com alguém que estava me dizendo: "Olha, parece que esse apelido da América não veio propriamente do fato de ser o Américo que começou aquelas viagens no final do século XV, XVI, que foi dar na tal da descoberta da América. Não foi propriamente o Américo que deu nome para a América. Em algum lugar da América Central, disso que é a América Central hoje, já em línguas originárias, em línguas daquela região do continente, tinha lugares na topografia que recebiam nomes, que eram nomeados por palavras que podem ter sido aliteradas e se transformado em “América'”. E parece que a palavra que originou esse apelido seria uma palavra: nérika. Nérika. E como tem muitas línguas, muitas, muitas línguas indígenas na região do México, Golfo do México, América Central, e essas línguas, essa relação tão grande de línguas nativas que sobreviveram ao primeiro ciclo da colonização, restaram poucas que ainda são faladas e que têm registros, menos ainda que têm registros escritos. Pelo fato de que nós sabemos que nenhuma das nossas tradições de povos indígenas daqui desse continente deixou registros escritos sobre a sua história, sua geografia, descrevendo seus territórios, essas narrativas elas ainda chegam, elas nos chegam através da oralidade, né? Da memória que foi sendo passada de geração em geração e chegou a alguns registros escritos, mas muito raros. Alguns registros escritos, mas que não alcançam uma descrição tão extensa de um continente do tamanho do nosso. Então eu fiquei instigado de fazer esse comentário sobre a "Abya Yala" com vocês, mas não é exatamente sobre isso que eu vou ficar falando por muito tempo pra vocês. Eu achei que era legal compartilhar com vocês, porque às vezes nós estamos em um espaço, ou estamos engajados em alguma iniciativa, e não tivemos a oportunidade de conhecer o que deu origem, ou que ideia, ou que evento que deu 
origem a essa nossa vinculação com uma legenda tão forte como essa "Abya Yala". No final da década de 70, começo da década de 80, tinha uma rede de pessoas indígenas que circulavam entre a Argentina, os Mapuche, alguns outros parentes de diferentes etnias aqui do Cone Sul, passando pelo Chile, Peru e chegando até o México, e constituindo uma rede que intentava recuperar um pouco as relações históricas que esses povos do continente experimentaram no tempo antigo, quando, segundo as narrativas, chegou a existir uma rede de povos que, desde lá do Equador, pegando um pouco o Panamá, o Equador, chegavam até aqui, na Argentina, com o nome de "tawantisuyu". Eu não sei se algum de vocês já ouviu essa expressão na língua quéchua: "tawantisuyu”. E por falar em línguas nativas, os Quéchua são falantes, são gentes de várias etnias, várias culturas, espalhadas entre o Equador, a Colômbia, o Peru, a Bolívia, chegando até mais abaixo da Bolívia, onde os povos têm essa língua comum, o quéchua. Eu acho interessante o fato de ter uma língua transnacional, uma língua que atravessa as fronteiras nacionais, as antigas fronteiras, e uma língua que dê unidade, digamos, territorial para os Andes todos. Nesse extenso território que constitui os Andes, e uma parte da selva também, quando desce para a Bacia Amazônica, viveram povos que compartilhavam a mesma língua, o quéchua. Do lado de cá, pegando aqui pelo Atlântico, com a chegada dos jesuítas por aqui e a coisa deles trabalharem uma gramática uniformizadora dos povos Tupinambá e Tupi, dessas línguas parentes do tronco Tupi, eles fizeram uma gramática do nheengatu, essa língua geral. Os jesuítas ensaiaram ela muito bem aqui nas Missões e despacharam ela depois para o resto da Costa Atlântica, chegando no Maranhão e subindo o Rio Negro. É interessante a trajetória dessas línguas faladas, não sendo língua materna, mas se constituindo em primeira língua de povos que deixaram de falar suas línguas originais para falar essa língua inventada pelos jesuítas, que é a gramática da língua geral, o nheengatu. Lá no Alto Rio Negro, você chega num lugar que tem uma cultura rica de vários povos, os Tukano, os Baniwa, os Dessana... Eu fiquei sabendo que meu amigo Gersem Baniwa passou por aqui esse mês. O povo do Gersem, por exemplo, além de falar baniwa, muitos deles também falam essa língua geral. A língua geral virou uma espécie de terceira língua em São Gabriel da Cachoeira, lá para cima do Rio Negro, Santa Isabel... Até as autoridades 
que iam botar quartéis lá, os militares que ficavam se estabelecendo naquela região, na década de 40,50,60, acabavam também aprendendo a falar língua geral para poder se comunicar melhor com a população local. Esse comentário sobre as línguas é uma oportunidade que vocês estão me dando de revisitar um assunto que eu acho muito importante, mas que ninguém dá muita bola para ele. Porque se dessem, as línguas indígenas não estavam em franco desaparecimento. Tem um relatório da UNESCO [Organização das Nações Unidas para a Educação, Ciência e a Cultura] que diz que, no Brasil, estão desaparecendo as línguas indígenas faladas por grupos indígenas, assim, de 80 indivíduos, 300 indivíduos, menos de mil, essas línguas estão desaparecendo em uma velocidade tão grande, que não dá tempo de registrar nem os últimos falantes. E para não dizer que é só um boato, eu confirmo para vocês que os Krenak, que é minha família, só tem 6 mulheres, com mais de 70 anos de idade, que falam a nossa língua fluentemente, que falam espontaneamente essa língua, sem pensar. Elas não precisam pensar porque essa é a língua que elas aprenderam com suas avós e com suas mães. Mas a minha geração - eu estou já com 62 anos -, eu não sou da geração de pessoas que cresceram falando a língua. Eu sou da geração dos que cresceu falando português, falando a língua regional dos nossos vizinhos mineiros que vivem no entorno do nosso rio, lá no Rio Doce, uma área que foi colonizada desde a década de 20 , no século passado, e que já tem mais de cem anos de colonização intensiva. Igual aqui no Rio Grande do Sul, onde vocês ocuparam territórios vizinhos às terras indígenas kaingang e mbyá-guarani, e que a presença tão próxima e que o assédio tão intenso da cultura regional abafa a expressão dessas línguas locais e, devagarzinho, vai erodindo a cultura desses pequenos grupos até o ponto de eles se integrarem na vida regional sem nenhuma particularidade. Onde os tais dos conhecimentos tradicionais sofrem uma erosão tão grave que nós em pouco tempo nos tornamos uma comunidade de iguais. Iguais no sentido de empobrecimento; quem dera que fôssemos iguais no sentido de compartilhar o que nós temos de melhor. Mas essa igualdade é uma igualdade com sinal de menos. A gente fica cada vez mais igual e cada vez mais pobres do ponto de vista cultural, do ponto de vista da diversidade, do conhecimento sobre os ecossistemas em que nós vivemos, da capacidade de interagir com os lugares em que nós 
vivemos e precisamos viver, com o lugar de onde nós tiramos água para beber, tiramos comida, tiramos tudo que a gente precisa para fazer nossos abrigos, para nos sentir bem, para nos sentir confortáveis. Então nós vamos, devagarzinho, fazendo desaparecer as paisagens em torno dos lugares onde nós vivemos, que é um espelho do outro desaparecimento, interior, que nos expomos a ele, e às vezes contribuímos para ele, que é a erosão cultural, né? É a perda de conhecimentos próprios sobre nossos hábitats, sobre nossas comunidades. No caso não só de comunidade humana, mas as comunidades em que nós nos constituímos, como culturas, e os ambientes que nós experimentamos. É interessante que aqui nos espaços em que nós estamos tendo essa oportunidade de encontro, nesse Instituto Latino-Americano de Estudos Avançados, vocês tenham a oportunidade de direcionar um pouco de estudos e de atenção para temas que não são muito privilegiados na maioria dos outros estudos que são realizados nas nossas universidades. Muito recentemente, só muito recentemente, é que as nossas universidades atentaram para a possibilidade de estabelecer troca com conhecimentos que não estão registrados, que não estão nos sistemas que o corpo de conhecimento das universidades foi constituindo. A maneira como essas instituições foram se consolidando acabou funcionando como maneira de exclusão e de diferenciação dessas sociedades em que nós nos constituímos e que são tão diversas, tão plurais, mas que essa máquina de seleção - que as nossas instituições, e as universidades estão entre elas, são máquinas de seleção -, ela foi selecionando só o que faz óbvia conexão e identidade com o complexo sistema colonial a que nós somos submetidos desde que nossos parentes chamaram essa terra de Abya Yala. E ela começou a receber vários outros apelidos, inclusive esse apelido que é muito caro a todos nós, que é "Brasil", que advém de um pau que eles tiravam aqui para colorir tecidos, que é o pau-brasil e que deu nome para esse lindo território que nós compartilhamos com nossos vizinhos da América Latina, orgulhosamente, depois de empurrar alguns deles para lá, como fez o Barão de Rio Branco, quando tomou o Acre da Bolívia, Boa Vista do Suriname, e nós fomos alargando nossos cotovelos, bem ao gosto colonial, alargando nossos cotovelos e empurrando os vizinhos mais fracos para o lado. Alguém pode falar: "Ah, mas o Ailton fica fazendo uma 
crítica tão aguda com relação a nossa memória e nossa herança cultural..." Eu peço a vocês que permitam que essa crítica seja feita, não a nossa herança cultural, mas a nossa herança colonial. Porque eu não creio que a gente tem que carregar de geração em geração os mesmos cacoetes daqueles que nos colonizaram, prestando um serviço de recolonização interna, como diz Boaventura Santos. O professor Boaventura Santos... Tem um colega que é aluno dele no pós-doutorado lá em Portugal, e ele sempre me aplica alguma qualidade sobre o tema. Felipe Milanez, seu nome. E ele me disse: "Olha, é impressionante quando você tem a chance de estar participando desse ciclo de debate, atualizando o seu conhecimento sobre nossa história colonial, como que você fica apto a identificar os cacoetes coloniais que a gente continua repetindo, como uma criança repete o gesto da mãe ou do pai". Como a gente imita o padrão colonial, reproduz, e nós viramos fiscais do pior. $\mathrm{E}$ quando nós discriminamos aqui no Brasil a expressão desses chamados povos tradicionais, sejam eles os quilombolas, os geraizeiros, que no caso é o pessoal que vive numa região lá do Estado de Minas Gerais, são microssistemas, ecossistemas, pedaços de faixas de sistemas territoriais que têm lá naquele sertão ali de Minas, que, aliás, é o território que o Guimarães descreve no Grande Sertão: Veredas. As veredas são como oásis nesse sistemas onde estão os geraizeiros e são microambientes onde comunidades humanas conseguiram viver no século XVII, século XVIII, século XIX, ficaram vivendo lá, criaram seus filhos, têm cultura, têm conhecimento sobre aquele lugar, são capazes de se reproduzir culturalmente ali, de dar conta deles mesmos... Aí chega a colonização ali, acaba com a confiança daquela gente. Transforma tudo num sistema de fabricação de pobreza. E aí, na virada do século XX para o século XXI, descobrimos ter uma capacidade enorme de fabricar pobreza, que é quando você chega em comunidades que ainda não têm dependência dessa coisa do fluxo do mercado, que são capazes de comer, beber, se vestir com as coisas que estão próximas deles, daqui a pouco eles estão subjugados por esse sistema de compensação do trabalho do mercado, mão de obra e tudo... E acaba que, por seu despreparo para esse modelo, são excluídos também, e eles vão para aquela lista dos pobres. Quando eu ouvi pela primeira vez essa ideia de fabricação de pobreza, eu achei que era só um slogan, alguém estava inventando uma frase, alguém 
estava inventando uma frase de efeito. Mas notei que, na verdade, é possível atestar que se pega uma comunidade que dá conta de viver ao longo de cem anos, e cem anos depois ela não consegue mais sobreviver sozinha, ela precisa ser assistida. Então, ao invés de as pessoas melhorarem, as pessoas estão piorando. E eu estou trazendo esse contexto para dizer que os índios nunca foram tão pobres como são nesse começo do século XXI. Quer dizer, nós estamos conseguindo transformar os índios do Brasil em pobres do Brasil. Tinha aquela lista dos 30 milhões de pobres abaixo da linha da pobreza, de repente a gente consegue fazer que sejam 50, 60 mil. Se a gente investir mesmo nisso, a gente consegue transformar todo mundo em pobre. E é uma falta de imaginação, porque a gente tem tantos exemplos recentes e mais antigos da nossa história que nos permitiriam pensar como que nós podemos, com essa diversidade cultural, valorizar sistemas de conhecimento que não estão nos cânones. Não só fazer de conta que ouve, mas realmente integrar esses conhecimentos, esses temas que podem ou que poderiam possibilitar, por exemplo, que não tivéssemos tanta dependência de comprar comida no mercado. Tem uns movimentos tímidos de pessoas procurando produzir seus alimentos e insistindo em comer alimentos saudáveis. Mas são muito poucos os que estão interessados em comer alimentos saudáveis e com coragem de não comer o veneno que está servido na mesa. As pessoas estão alertadas e sabem que a maior parte dos alimentos que são servidos na mesa estão com veneno, mas não têm coragem de arregaçar as mangas e dizer: "Não, nós vamos lutar para que continue tendo agricultura familiar, para que continue tendo espaços onde algum tipo de produção não dependente de agrotóxico, não dependente do sistema de venenos da agricultura intensiva, que está espalhada pelo nosso país e que está se configurando como uma espécie de poder político..." Porque eles tomam bancadas no Congresso, se intitulam "bancada ruralista". São reacionários, latifundiários, e se acham grandes contribuintes para o nosso "progresso", digamos assim. Eles são os nossos "patrocinadores". Então nessa posição de patrocinadores do nosso progresso, esses senhores se acham no direito de fazer todo o tipo de bárbarie, inclusive de mover um genocídio contra o povo KaiowáGuarani no Mato Grosso do Sul, justificando que esse ano eles exportaram 200 milhões de toneladas de grão, sendo que a maior parte desses grãos 
é soja. É monocultivo, usa veneno, envenena os mananciais, os corpos d'água, envenenam as pessoas diretamente, não precisa nem esperar para beber água depois, já pode beber o veneno direto. E só pelo fato dessa gente internalizar na economia brasileira alguns bilhões, eles se acham no direito de envenenar a gente. Isso é recolonização. Recolonizar é isso. Recolonizar é botar para dentro uma demanda que não é nossa, exportar nossa água e o nosso solo, criar pobreza nesses lugares, não dar oportunidade para essas pessoas se estabelecerem com dignidade. $\mathrm{E}$ o máximo que cabe para esses vizinhos desses empreendimentos é ser uma mão de obra barata, com o agravante de que as tecnologias hoje aplicadas nessa área, nessa produção em grande escala, cada vez mais ela dispensa a mão de obra humana e especializa o uso de máquinas, de outras tecnologias caras que a gente não fabrica, a gente compra. Então nós vamos criando esse círculo de dependência, onde os povos indígenas e os territórios onde os povos indígenas ainda conseguem subsistir estão se constituindo quase que como os últimos redutos onde a fauna e alguma biodiversidade pode subsistir. Para os biólogos, para o pessoal que trabalha com pesquisas na área de recursos florestais, no sentido geral, mas também para quem olha a biodiversidade, é claro que a nossa biodiversidade está sendo assaltada. Quando nós acabamos com nossas unidades de conservação, com os parques nacionais, com as reservas biológicas e botamos tudo isso num estoque de áreas não cultiváveis, elas ganham o sinal de menos porque elas não estão rendendo grana, e ganham um sinal de menos também porque o governo não tem o menor interesse em promover a proteção e a defesa desses territórios, dessas unidades de conservação. A política com relação a essas unidades de conservação, depois de aprovado aquele novo Código Florestal, rifou geral a mata ciliar, os topos de morro e algumas áreas de recarga onde as águas se organizam, abastecem nossos sistemas... Esses lugares estão sendo todos depredados. E a gente tem um Ministério do Meio Ambiente que prefere baixar resoluções dizendo que os índios não podem usar pena de arara para fazer cocar porque isso agride a fauna. Tem uma resolução do Ministério do Meio Ambiente que proíbe os índios de transitar por aí de cocar. Eu, inclusive, não estou com meu cocar aqui, porque podia, de repente, ser pego por infração ao meio ambiente. Estou fazendo uma brincadeira com vocês. Eu nunca usei um cocar com pena 
de arara porque os Krenak, o meu povo, não têm o costume de usar esses adornos com a pena das aves. Os meus parentes mais antigos, antes da gente aparecer nessa literatura do Brasil com esse nome, "krenak", vocês devem ter lido em alguma literatura um outro nome que nós tínhamos, que era "aimoré". E assim como nossos parentes xokleng de Santa Cataria e alguns kaingang, nós também éramos apelidados de "botocudos". Esse termo, "botocudo", ele, na colônia, no século XVIII, por aí afora, até o século XIX, ele era aplicado livremente aos Kayapó lá do Tocantins, naquele corredor lá do Araguaia, aos Xokleng de Santa Catarina, aos Kaingang do interior de São Paulo, e aos Aimoré, meus antepassados. Na verdade, esse "aimoré" também é um apelido, não é uma palavra da nossa língua, é uma palavra da língua tupi, porque os guias das expedições dos bandeirantes que entravam para dentro do sertão, iam do litoral para dentro do sertão, eles falavam tupi, e quando eles eram perguntados pelos seus patrões lá, pelos bandeirantes, "quem são aqueles camaradas que vivem lá dentro do Cerrado, lá naquelas serras?", os Tupi diziam para eles: "aimorê" ou "embaré". Aí eles estavam dizendo "gente do mato". Eu costumo brincar dizendo que esses índios do litoral sempre fizeram alguma discriminação com os índios lá do sertão, chamando a gente de caipira. Isso é uma velha prática carioca. Os cariocas ficavam ali em Copacabana, Ipanema servindo de batedor para os invasores e apelidando os caras de caipira. Mania carioca. Tem algum carioca por aqui? Eu achei que estava bem longe do Rio de Janeiro e podia fazer uma intriga carioca. Mas, se tiver algum carioca, por favor, me releva, está bom? Mas vocês imaginam que os índios que falavam tupi, quando perguntavam para eles quem eram os índios que estavam lá para dentro, nos campos lá para dentro do sertão, eles diziam que era "gente do mato". Eles diziam que era gente do mato, porque eles ficavam no litoral, e eles ficaram muito tempo no litoral. Eles só ficavam pegando praia, né, gente? Ficavam pegando praia nesse litoral todo. Acho que de Paranaguá, dessas praias maravilhosas de Paranaguá, até lá em cima, na Paraíba... Porque lendo um trabalho muito interessante, que vocês podiam ler uma hora se tiverem curiosidade, uma história da Mata Atlântica, com o título $A$ ferro e fogo, seu autor foi Warren Dean. O Warren Dean, ele é um camarada que morreu muito cedo, parece que com 47, 48 anos, escreveu esse monumento que é a história natural da Mata Atlântica. Ele conta a história da Mata Atlântica 
não do ponto de vista da colonização, mas ele conta a história da Mata Atlântica como a história geológica daquela formação. Como é que se formaram aquelas serras, aquelas paisagens, aquelas montanhas, como o complexo da Mata Atlântica se constitui, como na sua origem a Mata Atlântica empurrou o Cerrado, quando apareceram os primeiros hominídeos andando por ali e como teria aparecido um povo muito antigo, que são esses botocudos, há cerca de 16 mil anos atrás, empurrando os Tupi para dentro da região da Mata Atlântica. Então, nós somos inimigos históricos desses índios que ficavam na praia, é por isso que eles têm bronca da gente. É uma bronca de 12, 16 mil anos atrás que eles nunca esqueceram, para eles nós somos caipiras, porque empurramos eles para a praia. E se eles tivessem dado moleza, provavelmente a gente tinha jogado eles no mar. E os botocudos, que não eram mansos, decidiram que iam ficar vivendo num território que é entre o Rio Doce e o São Mateus. Esses dois rios, o Rio Doce e o São Mateus, eles saem das altas serras, lá daquela região onde está Ouro Preto, Mariana, Diamantina, são formações... O São Francisco também nasce lá naquelas serras, viu, gente? É uma região de formação de grandes rios nacionais. O São Francisco, o Rio Doce, o São Mateus, eles saem de lá daquelas serras da Mantiqueira, Espinhaço e ao lado tem outra formação, que é a Serra da Canastra. Então essas serras da Mantiqueira e do Espinhaço são duas formações centrais naquela região do nosso país, onde nasce muita água. Aliás, é lá naquele lugar em que nasce muita água que estourou uma barragem essa semana e matou um monte de gente, enquanto a mineradora que explora descaradamente esses mananciais, essas águas, esses lugares todos, nos últimos três anos consecutivos recebeu o prêmio de sustentabilidade ambiental. Levanta um troféu no final do ano, comemora o Natal, o Ano-Novo, e continua depredando a nossa paisagem. Então esses prêmios de sustentabilidade que vocês veem a maioria dessas corporações recebendo por aí, elas compram esses prêmios de sustentabilidade ambiental, porque quem confere esses prêmios é gente subordinada. Porque se nós tivéssemos um movimento ambientalista com vergonha na cara, a gente não deixava essas corporações ficar recebendo troféu. No mínimo, eles tinham que passar vergonha a cada balanço deles de encher o rabo de dinheiro e largar para trás um território destruído: com gente morta, soterrada, com a nossa 
água podre e envenenada, e não ficar elogiando e comemorando o faturamento desses caras. Na verdade os prêmios de sustentabilidade ambiental que eles recebem é um prêmio pelo lucro que eles têm. Só falta a gente criar um prêmio para o lucro dos bancos também. É certo que eles precisam receber um prêmio no final do ano. Afinal de contas, eles estão cuidando da gente. E viva a colonização! Ora, os Guarani, os Kaingang, os Tupiniquim que, aliás, "tupiniquim" virou um apelido pejorativo. As pessoas falam "ah, não sei quê lá, isso é tecnologia tupiniquim". Eu fui visitar esses nossos parentes chamados Tupiniquim. Os Tupiniquim vivem no Espírito Santo. Ali no litoral do Espírito Santo, saindo de Vitória, subindo para o norte do estado, indo para acima um pouco de onde deságua o Rio Doce, subindo para o lado do São Mateus. Os Tupiniquim quase que foram aniquilados pela colonização, mas eles sobreviveram. E é impressionante a resistência dessas pequenas comunidades, que chegam a ser reduzidas a uma centena de indivíduos, algumas dezenas de indivíduos, e que conseguem sobreviver, e conseguem manter sua memória. Porque sobreviver fisicamente já é um desafio, mas ainda manter a memória de você ter um coletivo de quase meia dúzia de pessoas que são capazes de reportar uma história comum, de dizer de onde vieram... Mesmo que eles só tenham cacos de uma língua materna, mas eles ainda conseguem repetir frases naquela sua língua materna como se fosse uma espécie de relíquia, guardada como uma espécie de última chance de continuar sendo gente, para não virar coisa, né? E encontrei os parentes tupiniquim no território de origem deles, brigando contra as indústrias de celulose. Pessoal que planta eucalipto, monocultura. Então a praga da monocultura, quando não é soja, ela é cana. Quando não é cana, é eucalipto. Qual que é a monocultura que chegou aqui no Rio Grande do Sul e está assolando o pampa? [Respostas do público: soja, eucalipto, outros] Então... Como se os nossos territórios, as nossas paisagens e a biodiversidade que nós temos, que é esse esplendor maravilhoso, fosse só um cenário para os outros chegarem aqui e implantarem as culturas deles. Um implante, né? Esse grande continente nosso é uma plataforma anônima esperando uma ocupação. Então, lembrando do debate sobre a descolonização, se tem alguma memória que a gente pode invocar e que vale a pena nós nos atribuirmos como nossa herança é essa de que mesmo as pequenas tribos 
que estão reduzidas a centenas de indivíduos continuam sabendo quem são, não querem se render e morrem, mas querem continuar tendo a possibilidade de escutar o barulho de seus riachos, de seus pequenos córregos correndo dentro de suas casas, dentro de suas moradias, como uma dádiva, como uma riqueza. Quando eles ainda podem fazer uma pequena armadilha de taquara e ir no igarapé pegar peixe e comer peixe. Entendeu? Comer peixe puro, peixe limpo. Não ficar comendo veneno. Não vão fazer um grande cultivo de nada, mas vão continuar tendo uma casa de farinha, vão plantar mandioca, vão fazer as suas farinhadas, as suas práticas da cultura, da dieta alimentar, da culinária. Dão conta de si em microssociedades, em pequenas comunidades. Que isso inspire a todos nós quando a gente se sentir muito chapado com a pressão colonial que esse período em que nós estamos vivendo imprime ao nosso cotidiano. Porque as mídias todas estão subalternas. Eu me lembro, que na década de 80, o jovem Rodrigo Vanzonni, que militava na ANAí [Associação Nacional de Ação Indigenista], estava ainda para decidir se ia fazer o curso de Direito, de Antropologia ou História, me acompanhava numa manifestação aqui em Porto Alegre. E nós fizemos uma manifestação na frente do Palácio Piratini. Na tarde em que a gente fez a manifestação, tinha uns três jornais entrevistando a gente na rua. Entrevistava e saía no jornal. Isso foi há 30 anos atrás. Hoje você pode fazer a manifestação, juntar o tanto de gente que você juntar, que não vai sair uma linha do que esse movimento social está falando, porque os jornais estão todos subordinados. E quando sai, sai uma matéria imbecil criminalizando o movimento social, dizendo que atrapalharam o trânsito. E a polícia vai lá e desce o cacete, joga gás lacrimogênio e tudo. Então nós estamos perdendo um espaço de cidadania, o que é gravíssimo. Estamos perdendo a nossa capacidade de mobilização e sensibilização dos coletivos a que nós pertencemos, ao mesmo tempo em que a gente perde território real, que é esses lugares da soja, do eucalipto, da cana, e de todas as monoculturas, que para nenhum de nós significa acrescentar nada na nossa lista da dieta alimentar e nada no nosso bem-estar, digamos, geral. Elas só significam um saque contra o nosso futuro. Eu sempre acho que para muitas pessoas imaginar um saque do nosso futuro pode parecer uma exagerada abstração. Mas como eles vão roubar o nosso futuro? Ora, roubam nosso futuro quando ignoram aquele conselho 
que aquele velho índio lá na costa dos Estados Unidos, num lugar chamado Seattle, que tem o mesmo nome desse chefe indígena que falou para o governo dos Estados Univdos: "Olha, se vocês nos tomarem essa terra em que nós vivemos, ensina para os seus filhos que essa terra é sagrada. Pisem com cuidado nessa terra. Se vocês não souberem reverenciar essa terra, e não entenderem que tudo que acontece com a terra, tudo que fere a terra, fere os filhos da terra, verão que um dia vocês vão despertar sufocados nos seus próprios detritos". Essa imagem é terrível. Roubar o futuro é isso. Roubar o futuro dos nossos filhos e dos nossos netos é conviver com a possibilidade dos nossos rios virarem esgotos. Olha o preço que nós estamos pagando. E as pequenas e grandes cidades do país também estão todas com rios podres. Parece que se tornou natural, nossos prefeitos pegam uma grana preta e mandam meter um concreto em cima de um rio podre e entuba o rio para ninguém ver que ali embaixo está passando um esgoto. Nós perdemos o controle social sobre os nossos representantes, eles fazem o que querem. Se os camaradas chamam a gente no dia 15 de novembro ou 05 de novembro, ou outubro, a cada turno, pegam nosso voto e depois eles fazem o que querem com os mandatos que nós atribuímos a eles para fazer todo o tipo de besteira, inclusive mudar o Código Florestal, como fizeram descaradamente. E agora fazendo novas mudanças, tentando imprimir na Constituição de 88 emendas que atendem só o interesse particular desses indivíduos e seus grupos, como se a Constituição do Brasil fosse uma carta de condomínio. O Brasil é o condomínio desses caras e eles nomeiam o síndico e aplica no síndico e o síndico vai lá, entra na Constituição, corta com uma emenda. "Que mais você quer aqui, meu filho?" "Ah, agora troca o elevador". Nós não podemos deixar que essa recolonização se consolide de uma maneira tão automática e que isso vire uma coisa natural, porque os nossos filhos e nossos netos é que vão herdar esse futuro duvidoso, além desse lugar que nós aprendemos a amar, que são os lugares dos rios, das florestas, das montanhas serem também apropriados por gente que não sabe cuidar deles. Que vão estragar essas paisagens cada vez mais. Eu não sei se as paisagens em que vocês nasceram ou cresceram têm tanta importância para o seu bemestar emocional, para seu equilíbrio pessoal, mental. Mas para mim têm. E eu me incomodo muito de assistir a mudança das paisagens quando a 
gente se desloca. À semelhança dos rios que ficam podres e chegam a feder, algumas das nossas serras e montanhas viram pesadelos depois que metem as máquinas nelas e cortam nossas montanhas, como se qualquer um pudesse se apropriar da paisagem. $O$ tal do patrimônio cultural. $O$ tal do patrimônio cultural que a gente não tem nenhuma relação direta com ele. Ele é apropriado o tempo inteiro da maneira mais indecente, grosseira. E a gente deixa barato. Tem um poeta... os poetas morrem mas continuam vivos de alguma maneira, então o Drummond está vivo. Ontem eu falei com uma amiga minha que o Drummond se exilou de Minas Gerais porque ele não aguentava mais aquela mentalidade extrativista garimpeira. Mas tem um poema do Drummond que descreve a cidade natal dele, que é Itabira, dizendo o seguinte: "Itabira, 70\% de ferro nas calçadas e 30\% de ferro nas almas". Sentiram o peso? Ele estava falando da paisagem do lugar onde ele nasceu. Esse é um fragmento de um poema do Carlos Drummond de Andrade. "70\% de ferro nas calçadas, $30 \%$ de ferro nas almas". Não sei se alguém leu o Drummond a ponto de lembrar um poema dele, mas ele fala que "ah, mas a minha cidade hoje, agora, é só um retrato na parede". Porque a paisagem mesmo já dançou, então fica um retrato na parede. Esse território que o Drummond canta, antes de ser o lugar onde ele nasceu, onde a família dele foi viver, foi também um território dos botocudos. Assim como Ouro Preto, Mariana, Diamantina. Dizem que em 1612, quando os franceses tentaram fazer uma mina de diamante lá nesse lugar que virou Diamantina, eles levaram um revés, e os portugueses acabaram tendo a sorte de ir depois e abrir o garimpo e dar certo, e virar Diamantina, que foi essa grande mina de diamante, na divisa já do Sertão Mineiro. Seguindo em frente ia sair lá na Chapada Diamantina, na Bahia, esse grande maciço. Os botocudos estavam lá naquela região onde fizeram o garimpo de Diamantina, quando o grupo de garimpeiros que não eram portugueses se estabeleceram lá e tentaram fundar uma cidade. Os botocudos teriam descido o cacete neles, expulsando eles dali. Mas não tinham experiência de vigiar aquele lugar, se deslocaram para outros vales, para outras cabeceiras de rio. Esse grupo de aventureiros foi embora, mas os portugueses chegaram um pouco depois e abriram essa vila que deu mais tarde em Diamantina. Muitas dessas cidades coloniais mineiras nasceram de garimpo, nasceram da atividade da mineração, da 
extração de ouro e de diamante, mas antes disso, eles tiveram que expulsar os índios de lá. Um pouco dessas memórias, e um pouco dessas falas que eu estou compartilhando com vocês, vão poder ser achadas com mais detalhe naquele livrinho que eu fiz pela Editora Azougue, na companhia de muitos outros ilustres autores, é o de número 50 de uma coleção que se chama Encontros. Reúne entrevistas feitas comigo por vários autores e que teve edição e organização do editor Serio Cohn. Estas entrevistas feitas entre 84 e 2013. O editor apanhou tudo o que eu tinha falado em entrevistas nesses últimos 30 anos e selecionou as que estão aqui. Eu não participei da escolha. Quando ele me apresentou o projeto editorial, eu achei uma novidade. Tinha muitas coisas que eu tinha falado há 20 anos atrás e sempre dá um pouco de... dá uma friagem na barriga você ver uma coisa que você falou há 20,30 anos atrás, ainda mais quando você só falou, não escreveu. Mas que aparece depois, assim, gravado em letrinhas, e talvez por eu ter mais uma experiência de oralidade, de fala, e menos experiência de escrita, esse efeito da escrita sobre mim tem um impacto grande. Aqui tem uma frase que está dizendo assim: "Para mim e para meu povo, ler e escrever é uma técnica, da mesma maneira que alguém pode aprender a dirigir um carro ou a operar uma máquina. Então a gente opera essas coisas, mas nós damos a ela a exata dimensão que têm. Escrever e ler para mim não é uma virtude maior do que andar, nadar, subir em árvores, correr, caçar, fazer um balaio, um arco, uma flecha ou uma canoa". Eu olhei isso aqui e falei: "Com que situação eu me meti a falar sobre isso?". Aí tem uma entrevista mais longa, ali onde aparece falando sobre esse negócio da escrita. Eu vi que estava dando uma entrevista para uma revista especializada em escola, chamada Nova escola, que era dirigida a educadores. Houve um tempo no Brasil = senta que lá vem história - em que estava em questão a educação. Se a educação escrita, leitura escrita... Essa educação que nós chamamos de "educação básica". E os educadores, naquele tempo, eles eram tão sonhadores que eles acreditavam que podiam criar uma escola, outras escolas. Que eles não tinham que entrar no modelo de educação que o Brasil estava constituindo e consolidando, espalhando pelo Brasil afora, essas nossas escolas públicas ou mesmo as escolas que não são públicas, as escolas das missões, as escolas particulares, mas essas escolas rodam todas o mesmo disco. Quer dizer, muda de endereço, mas roda o mesmo 
disco. E por orientação do Ministério da Educação, e mais tarde pela Lei de Diretrizes Básicas da Educação, a tal da LDB, né? 90 e poucos... Essas implementações retardadas do sistema todo... Mas lá na década de 80 já tinha muitos professores rebeldes que saíam dessa e criavam escolas. Criavam escolas. Teve muitas experiências de criação de escola. Grupos de amigos, de colegas que eram educadores se juntavam e criavam escolas. Parece que depois da LDB nem essa possibilidade continuou mais existindo, de as pessoas se rebelarem e criarem uma escola. Agora mesmo que você se rebele você vai criar uma escola igualzinha a outras que já existem. Porque senão você não vai dar certificado para o aluno, ele não vai concluir a formação dele e depois ele só pode fazer o caminho, digamos, de autodidata dele. Porque o sistema de educação não admite essas autonomias. Foi nesse contexto que uma pessoa me perguntou: "Ailton, o que você acha da alfabetização para as crianças indígenas?" Aí eu falei para ele: "Para quê?" Aí ele falou: "Se os indígenas souberem ler e escrever, já pensou como eles vão poder se defender, como eles vão poder se preparar melhor para enfrentar os seus inimigos?" Eu questionei muito essa história de alguém aprender a ler ou escrever, essa coisa da escrita. E eu nunca parei de pensar sobre esse dilema, mesmo quando o Cristóvão Buarque foi Ministro da Educação do Lula, no primeiro mandato dele, o Cristóvão, que eu sempre admirei muito, cometeu uma grave frase, onde ele disse: "Em 5 anos nós vamos acabar com o analfabetismo no Brasil". Eu olhei e falei: "Como é que um cara genial como o Cristóvão Buarque pode falar uma besteira tão alarmante?" Porque se você pensa esse país nosso fazendo uma campanha para não deixar ninguém sem a prática da escrita e da leitura, significa que você vai colonizar os últimos redutos de memória decente que ainda não foi invadido pela palhaçada colonial que domina todo o mundo, desde a religião até o consumo do último biscoitinho do mercado. Aí você vai realmente assolar as pessoas, as nossas avós, as nossas tias, os nossos avôs, os nossos padrinhos, aquelas pessoas que sabem benzer alguém, aquelas pessoas que sabem curar alguém, sabem fazer um chá, fazer um remédio. Essas pessoas todas são esses "ignorantes analfabetos" que o Cristóvão queria acabar com eles. Mas eu tenho certeza que o Cristóvão é uma boa pessoa e ele só falou uma besteira. Então nessa oportunidade de encontro com vocês eu me senti tão à vontade, gente, que eu falei tudo que o rosto de vocês 
me inspirou a falar. Muito obrigado por vocês ficarem me ouvindo, está bom?

Recebido em: 25/11/2015 * Aprovado em: 23/12/2015 * Publicado em: 31/12/2015 